\title{
Os fascinantes juros biológicos: entre a sofia e o sofisma
}

Nilson José Machado

$T^{\prime}$ AL como já o fizera com Auto-engano e com Felicidade, o economistamista Eduardo Giannetti volta a nos brindar com mais um instigante livro, sobre tema complexo e candente: $O$ valor do amanhã. Trata-se, supostamente, de um livro sobre juros, e somente um autor naturalmente sedutor e extremamente competente poderia conjuminar um tema tão carente de poesia com as indiscutíveis qualidades que certamente o texto ostenta: a linguagem é clara e distinta, sem recorrer a tecnicidades; é pleno de relações inspiradoras, que extrapolam em muito o universo da economia, sem derrapar em banalizações abusivas; a abordagem é brilhante em muitos aspectos e original em múltiplos sentidos. Sem dúvida, o livro de Giannetti merece todos os qualificativos citados. A única questão em aberto é a seguinte: trata-se realmente de um livro sobre juros?

$\mathrm{O}$ autor jura que sim. Mas o conceito de juros que apresenta é tão abrangente, extrapola tão desinibidamente o universo da economia e imiscui-se em terrenos tão insuspeitados, que da surpresa inicial somos conduzidos à natural demanda de uma reflexão a respeito. É como se um dentista examinasse a problemática odontológica a partir de um conceito de dente tão amplo que incluísse dos dentes humanos aos dentes de uma engrenagem ou de um serrote: o fascínio da generalização sintética não nos poderia dispensar da análise da pertinência da opção realizada.
De fato, desde as páginas iniciais o autor anuncia que vai enraizar a noção de juros no terreno da biologia, apresentando-a como um elemento natural nos processos vitais. Os juros seriam inerentes a todas as trocas intertemporais: viver agora, pagar depois, ou pagar agora, viver depois seria a matriz básica de onde eles derivariam. Nas palavras do autor,

o fio condutor do argumento desenvolvido no livro é a noção de que a realidade dos juros não se restringe ao mundo das finanças, como supõe o senso comum, mas permeia as mais diversas e surpreendentes esferas da vida prática, social e espiritual, a começar pelo processo de envelhecimento a que nossos corpos estão inescapavelmente sujeitos. A face mais visível dos juros monetários - os juros fixados pelos bancos centrais e aqueles praticados nos mercados de crédito - representa apenas um aspecto, ou seja, não mais que uma diminuta e peculiar constelação no vasto universo das trocas intertemporais em que valores presentes e futuros medem forças. (p.10)

A inexorabilidade e a onipresença do fenômeno dos juros é incisivamente afirmada na comparação desses com o processo de envelhecimento:

a juventude não é gratuita: ela resulta de uma antecipação de valores à custa de prejuízos futuros. A senescência dos organismos é a conta de juros decorrente do redobrado vigor e aptidão juvenis. Assim como a gravidade, a fotossíntese e as mutações genéticas, para lembrar fenômenos que indepen- 
dem da presença humana no mundo, os juros são parte da ordem natural das coisas. (p.12)

Como não existem alternativas para o envelhecimento humano, nem para os demais fenômenos mencionados, resta-nos relaxar e fruir a leitura em busca de uma compreensão do fenômeno dos juros que nos alente, ou que nos console. Mas o autor continua sua surpreendente trilha, ampliando o conceito de vida para muito além da vida humana, e afirmando que o envelhecimento não é inevitável - ou pelo menos não era, até o advento da reprodução sexuada. Em suas palavras,

No princípio, era a imortalidade. O que não vive, é certo, não morre... A vida é concebível sem a inexorabilidade da morte, e, de fato, assim parece ter sido durante o primeiro bilhão de anos em que a vida surgiu e se propagou sobre a Terra [...] Se a finitude biológica, tal como a conhecemos, não é contemporânea da vida, então como nasceu a morte? [...] Com o sexo, nasce a morte [...] A finitude biológica é o preço de uma aposta premiada. (p.21-8)

Em outras palavras, a mortalidade embute os juros que a imortalidade cobra pelos prazeres e conveniências da reprodução sexuada...

A religião também não escapa à abrangência do conceito de juros do autor, como se pode depreender do trecho seguinte:

Quando os juros infinitos da bemaventurança eterna estão em jogo, não há sacrifício ou renúncia que não pague a pena. O contrato implícito nas cinco grandes religiões mundiais - "obediência agora, salvação no porvir” - expressa essa realidade. (p.12)

A construção paulatina dessa pregnância dos juros nos mais diversos ce- nários constitutivos da vida humana é impressionante no percurso do autor: vivemos, respiramos, transpiramos, sofremos, sonhamos, cultivamos, calculamos, descontamos continuamente. Viver agora, pagar depois; ou pagar agora, viver depois, eis a grande questão. A vida decorreria do jogo de forças de vontade, da paciência ou da impaciência na realização de nossos desejos. Ao resumir nossas decisões ao putativo dilema - acumular agora para desfrutar no futuro, ou desfrutar agora e pagar no futuro -, aceita-se tacitamente a pressuposição de que do jogo dos juros emerge o sentido da vida. É duro, é pobre, parece pouco.

A síntese giannettiana é brilhante, no entanto, na explicação de certos mecanismos psicológicos presentes nas decisões econômicas. Outras dimensões das motivações das ações humanas são, no entanto, solenemente ignoradas. Há muito o universo da economia e o discurso econômico reconhecem a existência e a importância, por exemplo, da permanência da dádiva no seio da circulação mercantil. Desde que Marcel Mauss chamou a atenção para a importância do fenômeno em seu seminal Essai sur le don (1924), inúmeros importantes autores debruçaram-se sobre o tema, produzindo reflexões econômicas tão instigantes quanto as de Giannetti, mas que, sem negar as premissas do mercado, incorporam a perspectiva maussiana, examinando as implicações teóricas e práticas da pregnância da circulação dadivosa. L'esprit $d u$ don (1992), de Jacques T. Godbout, traduzido e publicado no Brasil pela Editora da Fundação Getúlio Vargas, é um exemplo expressivo da relevância da temática. Outros exemplos são The 
Economy of Love and Fear (1973), de Kenneth E. Boulding, e Knowledge assets (1998), de Max H. Boisot.

Os exemplos poderiam ser multiplicados sem nenhuma dificuldade. Giannetti, no entanto, ignora completamente tal perspectiva. O protagonismo em termos de problemática econômica situa-se, em sua visão, no dilema acumular/desfrutar; a questão da atribuição de valor ao conhecimento, hoje transformado, sem dúvida, no principal fator de produção, bem como a questão da correlata problemática da "distribuição" de tal "bem" representam papéis de meros coadjuvantes.

Tal omissão, lamentavelmente, empobrece as análises do autor. Brilhantes na dimensão psicológica e na redução que operam, traduzindo a vida como um mero jogo, deixam lacunas nada desprezíveis, ao silenciar sobre a dádiva como elemento fundamental da criação de laços, como motivação essencial na constituição da humanidade do ser humano. Os mecanismos de subestimação do futuro, criativamente denominado de miopia, ou de superestimação do futuro, similarmente chamado de hipermetropia, tão competentemente descritos pelo autor, talvez se situem na ante-sala das questões realmente decisivas na determinação das ações humanas, ou pelo menos, talvez, devessem partilhar espaços com outra classe de preocupações.

Sem dúvida, Giannetti examina com intuição e perspicácia uma realidade efetivamente existente; é possível, no entanto, que ele tenha apreendido e descrito com perfeição o funcionamento de um aparelho que trata como se fosse um aquecedor de ambientes, mas que poderia se tratar, de fato, de uma simples geladeira, numa possível inversão entre meios e fins. Afinal, entre a mordaz caracterização orteguiana do comerciante como el tipo inferior del hombre (O.C., v.2, p.299), e a reivindicação maussiana de que não temos apenas uma moral de mercadores, existe um considerável espaço em que uma mente lúcida como a de Giannetti poderia construir insights reveladores da riqueza multifacetada da natureza humana.

Ao longo de todo o livro, são constantes as referências à peça $O$ mercador de Veneza, de Shakespeare, sugerindo que o autor a considera emblemática, na análise da problemática dos juros. Ocorre que, literalmente, o empréstimo de 3.000 ducados pelo prazo de três meses, feito por Shylock a Antônio, que o repassará a seu amigo Bassânio, é anunciada como literalmente sem juros (O.C., v.2, p.439): o ódio antigo que o credor alimenta pelo devedor é o motor do empréstimo, que se caracteriza, desde a origem, como uma ocasião propícia para uma vingança. A peça não retrata uma típica troca intertemporal, com a justa remuneração pela impaciência do devedor e/ou pela paciência do credor. Tanto é assim que, findo o prazo, o devedor tenta devolver a quantia em dobro, para compensar amplamente o credor, mas Shylock não aceita, reivindicando sua libra de carne do devedor. Na extensão metafórica do significado dos juros realizada pelo autor, tal libra de carne constitui, na verdade, os juros devidos; no cenário shakespeariano, trata-se, no entanto, da mera concretização de uma vingança cruelmente projetada, em uma trama muito bem urdida, bem distante do terreno da economia. Convenhamos 
que caracterizar tal retribuição compulsória de carne e sangue como juros é afastar-se significativamente do terreno da aceitação branda e inexorável de tal noção, em razão de sua associação com os processos vitais, com os modos naturais de ação humana.

Ainda que pretenda, desde as páginas iniciais, tratar da realidade dos juros na economia, é na quarta parte do livro ("Juros, poupança e crescimento") que o autor pretende aproximar-se mais decisivamente da problemática da economia brasileira, respondendo ao desafio de entender "por que os juros no Brasil permanecem cronicamente altos" (p.14). Seria justo esperar-se do autor, nessa parte, um mergulho teórico que se afastasse um pouco da brandura das metáforas biológicas e desse conta da especificidade dos juros monetários, com sua pretensão de justa remuneração do capital. Não é, no entanto, o que exatamente ocorre. As reflexões do autor permanecem no terreno da avaliação das "variações do grau de impaciência" dos indivíduos envolvidos no jogo de trocas, pressupondo-se que nada existiria de problemático na natureza de tal jogo.

As "conclusões principais" a que chega, ao final do livro, são duas. A primeira refere-se à tentativa de entender as diferenças nos graus de impaciência de cada grupo social em razão de determinantes históricos. Em suas palavras,

Quando o forte apego de um grupo social ao máximo (desfrute) local, em claro prejuízo dos seus interesses de mais longo prazo, resulta de condições prévias marcadamente injustas e opressivas, o livre jogo das trocas no mercado de crédito, apesar de legal e voluntário, desperta sérias dúvidas do ponto de vista ético. A existência de uma enorme e secular desigualdade de renda, associada a uma não menos profunda assimetria de oportunidades educacionais, pode levar um grupo social a explorar outro grupo e se beneficiar injustamente dele, sem ferir as regras formais da livre escolha. A injustiça aqui não está tanto na distribuição de ganhos da troca - embora ela acabe espelhando o vício de origem - mas na notória falta de legitimidade do caminho que levou até essa distribuição. (p.275)

Como se vê, a pressuposição é a de que o jogo nada tem de intrinsecamente problemático: as condições iniciais dos jogadores é que produzem e determinam as injustiças. Existem, no entanto, controvérsias a respeito. Desde o momento em que o conhecimento se transformou no principal fator de produção, sua “distribuição" passou a enfrentar problemas novos, insuspeitados na dinâmica mercantil das trocas, que conduzem a verdadeiros paradoxos. De fato, o conhecimento é um "bem" que podemos dar, vender ou trocar sem ficar sem ele; é uma "mercadoria" de que não se pode falar em estoque; é um "material" que quanto mais é usado, mais novo fica etc. Problemas crônicos de atribuição de valor ao conhecimento não parecem passíveis de serem minimamente tangenciados, quando são levadas em conta apenas as diferenças nas condições iniciais de participação de cada sociedade no livre jogo das trocas.

A segunda das conclusões apontadas pelo autor refere-se à diferença na orientação para o futuro, em sentido econômico, entre duas sociedades distintas. Ele pergunta:

Até que ponto ela reflete uma escolha autônoma baseada em valores ou uma

Estudos Avançados 20 (57), 2006 
falta de opção, isto é, a influência de fatores cerceadores que impedem a sociedade de afirmar suas preferências e encontrar seu grau desejado de cuidado com o amanhã? (p.276)

A resposta que dá a tal questão reforça o que anteriormente se afirmou, ao final da primeira conclusão; segundo o autor, tudo depende

(a) das condições em que se formam o horizonte e o modo de lidar com o futuro na sociedade (psicologia temporal dos jogadores), e

(b) das características do seu ambiente institucional (regras do jogo). (p.276)

Como se pode depreender, as conclusões reforçam a caracterização da vida prefigurada ao longo de todo o texto, como um mero jogo de trocas, desprovido de qualquer dimensão teleológica. Trata-se, sem dúvida, de uma posição respeitável do ponto de vista filosófico, nada havendo a contestar. Entretanto, para quem já pretendeu entusiasmar o leitor com o exercício apaixonado da filosofia, como o autor o fez, por exemplo, em Felicidade (2002), resta um gosto amargo na boca, ao final da leitura. Não se trata, obviamente, de se reclamar uma perspectiva panglossiana, ou uma cândida visão da economia; uma mínima possibilidade de abertura que poderia resultar, por exemplo, da inclusão da circulação dadivosa em seu universo reflexivo não seria, no entanto, indesejável.

Afinal, se a vida não passa de um mero jogo de trocas intertemporais, em que usufruir agora ou depois é a única alternativa que se prefigura, então fica difícil compreender o indiscutível bom humor do autor, e a fina ironia com que constrói suas argumentações muito bem elucubradas. Seria como se a sofia entregasse os pontos e perdesse o jogo para o simples sofisma.

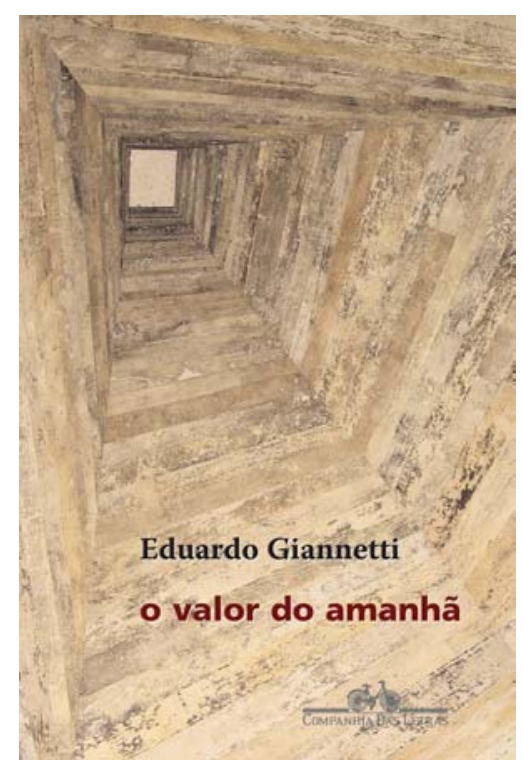

GIANETTI, E. O valor do amanhã. São Paulo: Companhia das Letras, 2005. 337p.

Nilson José Machado é professor na Faculdade de Educação da USP.

@ - njmachad@usp.br 